\title{
Supporting Information of
}

\section{Realizing the Single-Phase Spinel-Type Sodium \\ Titanium Oxide with the $\mathrm{Li}_{4} \mathrm{Ti}_{5} \mathrm{O}_{12}$-like Structure for Building Stable Sodium-Ion Batteries.}

\section{AUTHORS}

Mitsunori Kitta $^{1}$, Toshikatsu Kojima ${ }^{1}$, Riki Kataoka ${ }^{1}$, Koji Yazawa ${ }^{2}$ and Kohei Tada ${ }^{1}$

\section{AFFILIATION}

${ }^{1}$ Research Institute of Electrochemical Energy, Department of Energy and Environment, National Institute of Advanced Industrial Science and Technology (AIST), 1-8-31 Midorigaoka, Ikeda, Osaka 563-8577, Japan

${ }^{2}$ JEOL RESONANCE Inc., 3-1-2 Musashino, Akishima, Tokyo 196-8558, Japan

\section{KEYWORD}

sodium-ion battery, negative electrode materials, spine-type sodium titanium oxide, $\mathrm{Li}_{4} \mathrm{Ti}_{5} \mathrm{O}_{12}-$ like structure, single-phase preparation, stable sodium intercalation host material, $3 \mathrm{~V}$ class oxide-based sodium-ion battery 
(a)

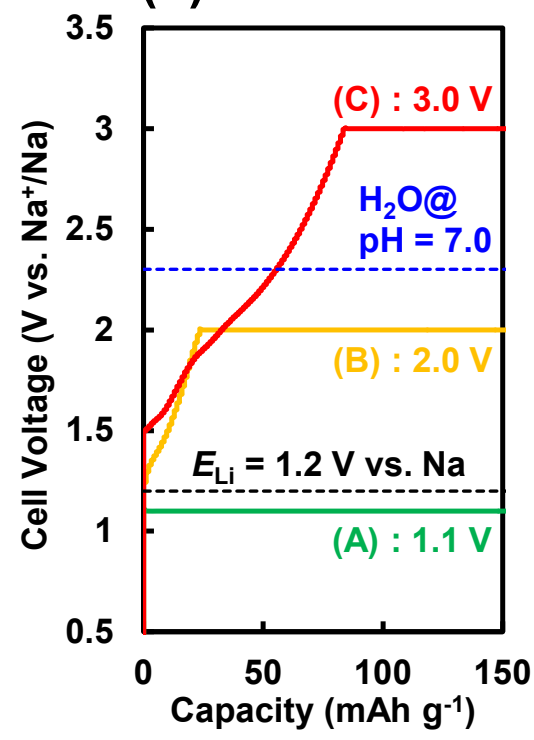

(b)

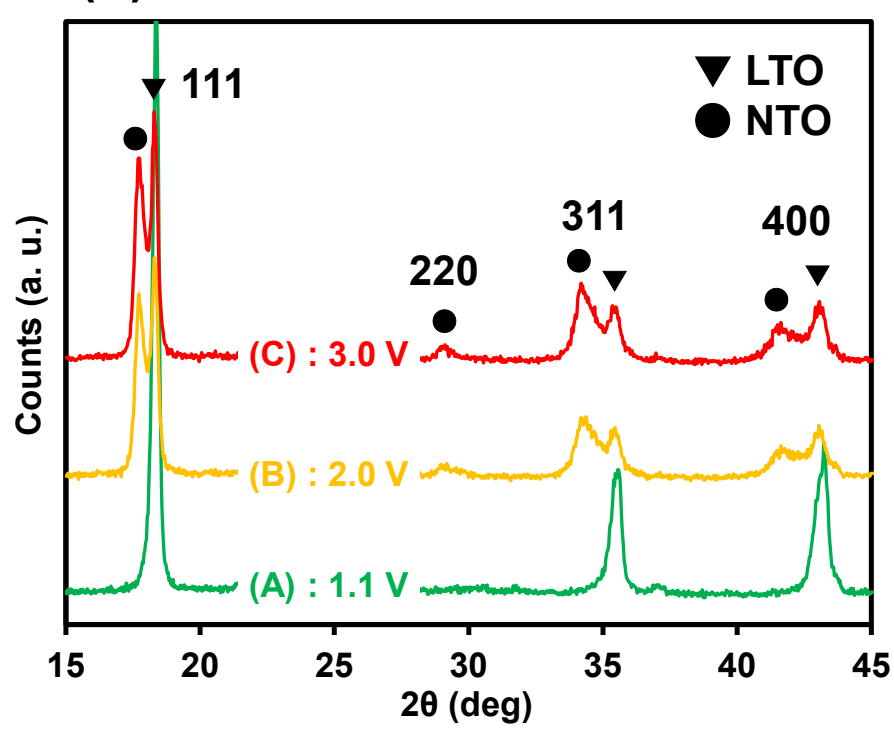

Figure S1 Discussion of NTO phase formation and oxidation potential. (a) Electrode oxidation voltage profiles of each precursor (Na-inserted LTO) electrode under various constant voltage condition. All the precursor electrodes were prepared by electrochemical Na-insertion into LTO with each LTO / Na half-cell. At first each cells were kept at $0.3 \mathrm{~V}$ vs. $\mathrm{Na}^{+} / \mathrm{Na}$ voltage for $48 \mathrm{~h}$ to complete Na-insertion. Then prepared precursor electrodes were oxidized with 10 C-rate constant current condition till reached various constant voltage condition for (A) $1.1 \mathrm{~V}$, (B) 2.0 $\mathrm{V}$, (C) $3.0 \mathrm{~V}$ vs. $\mathrm{Na}^{+} / \mathrm{Na}$. Li-extraction potential $\left(E_{\mathrm{Li}}\right)$ is presented with black dots line as $1.2 \mathrm{~V}$ vs. $\mathrm{Na}^{+} / \mathrm{Na}$ in the LTO / Na half-cell. Note that the Li-extraction potential $\left(E_{\mathrm{Li}}\right)$ in $\mathrm{LTO} / \mathrm{Li}$ half-cell $\left(1.55 \mathrm{~V}\right.$ vs. $\left.\mathrm{Li}^{+} / \mathrm{Li}\right)$ is equal to $1.2 \mathrm{~V}$ in $\mathrm{LTO} / \mathrm{Na}$ half-cell, as the different electrochemical potential of $\mathrm{Li}(-3.045 \mathrm{~V}$ vs. NHE) and $\mathrm{Na}(-2.714 \mathrm{~V}$ vs. NHE).

The water oxidation potential is altering with $\mathrm{pH}$ condition as follows,

$$
E_{\text {water }}=0+\frac{R T}{n F} \ln \left[H^{+}\right] \text {vs. NHE }
$$


Where, $R$ and $F$ are gas and Faraday constant, respectively. Above equation can be written as follows at $T=298 \mathrm{~K}$.

$$
E_{\text {water }}=0-0.0592 \mathrm{pH} \quad \text { vs. NHE }
$$

Therefore, the oxidation potential of neutral water $(\mathrm{pH}=7.0)$ is estimated as $-0.4144 \mathrm{~V}$ vs. NHE. This means that the neutral water has $2.3 \mathrm{~V}$ vs. $\mathrm{Na}^{+} / \mathrm{Na}$ of oxidation potential as presented with blue dots line in (a). (b) XRD profiles of oxidized electrode corresponding to (a). The $\mathrm{Cu}-\mathrm{Ka}$ X-ray source $\left(\lambda_{1}=1.5405 \AA, \lambda_{2}=1.5443 \AA\right)$ was used for this experiment. XRD profiles of oxidized electrode with $1.1 \mathrm{~V}$ vs. $\mathrm{Na}^{+} / \mathrm{Na}$ did not show the peaks of NTO phase $(\mathbf{O})$, suggested that the electrode completely revert to single LTO phase due to the oxidation potential not exceeded Li extraction potential. Both the electrodes oxidized with $2.0 \mathrm{~V}$ and $3.0 \mathrm{~V}$ vs. $\mathrm{Na}^{+} / \mathrm{Na}$ electrochemical potential clearly shows the peaks of NTO phase. The Li extraction from precursor electrodes is essential key for NTO phase formation and $2.0 \mathrm{~V} \mathrm{vs}$. $\mathrm{Na}^{+} / \mathrm{Na}$ of oxidation potential was enough to that $\mathrm{Li}$ extraction. Therefore, neutral water $(\mathrm{pH}=7.0)$ should be work as the effective oxidant for precursor to NTO formation. 


\begin{tabular}{|c|c:c|c|c|c|c|}
\hline \multirow{2}{*}{$\begin{array}{c}\text { Cycle } \\
(\mathrm{n})\end{array}$} & \multicolumn{2}{|c|}{ Lattice Constant $(\AA)$} & \multicolumn{2}{c|}{ Phase Ratio (\%) } & \multicolumn{2}{c|}{ 400 peak of NTO phase } \\
\cline { 2 - 8 } & LTO & NTO & LTO & NTO & $\begin{array}{c}\text { Intensity } \\
(\mathrm{cps} \cdot \mathrm{deg})\end{array}$ & $\begin{array}{c}\text { FWHM } \\
(\mathrm{deg})\end{array}$ \\
\hline 0 & 8.362 & - & 100.0 & 0 & - & - \\
\hline 1 & 8.363 & 8.707 & 62.4 & 37.6 & 4426 & 0.381 \\
\hline 3 & 8.376 & 8.739 & 49.7 & 50.3 & 7353 & 0.226 \\
\hline 5 & 8.374 & 8.733 & 22.6 & 77.4 & 10954 & 0.134 \\
\hline 7 & 8.468 & 8.757 & 13.6 & 86.4 & 11245 & 0.077 \\
\hline 9 & 8.399 & 8.748 & 8.6 & 91.4 & 11873 & 0.081 \\
\hline
\end{tabular}

Table S1 Parameters of SR-XRD profiles in each purification cycles. 0 cycled sample $(n=0)$ shows pristine LTO material. The lattice constant of LTO phase is almost constant during the purification process, while that of NTO phase is gradually increasing till 3rd cycle. Phase ratio of LTO and NTO phase is normalized at $($ LTO + NTO $=100 \%)$, clearly showed that LTO phase is decreasing while NTO phase is increasing with purification cycles. The LTO phase clearly convert to NTO phase, which is also confirmed by the increments of integral intensity of NTO 400 peak. The crystallinity of NTO phase is evaluated by the full width at half maximum (FWHM) of 400 peak, where the value is decreasing with purification cycles, suggesting the crystallinity of NTO phase should be increasing with phase purification. In the insufficient phase purification state ( $\mathrm{n}=1$ to 5 ), there non-negligible amount of LTO phase is included in the single particles, and this phase composite condition would be affect the crystallinity of NTO phase due to the lattice strain. The sufficient purification ( $n=7$ to 9 ) enhance the crystallinity of NTO phase, since almost all the particle region is NTO phase, releasing the lattice strain. 


\section{(a): LTO}

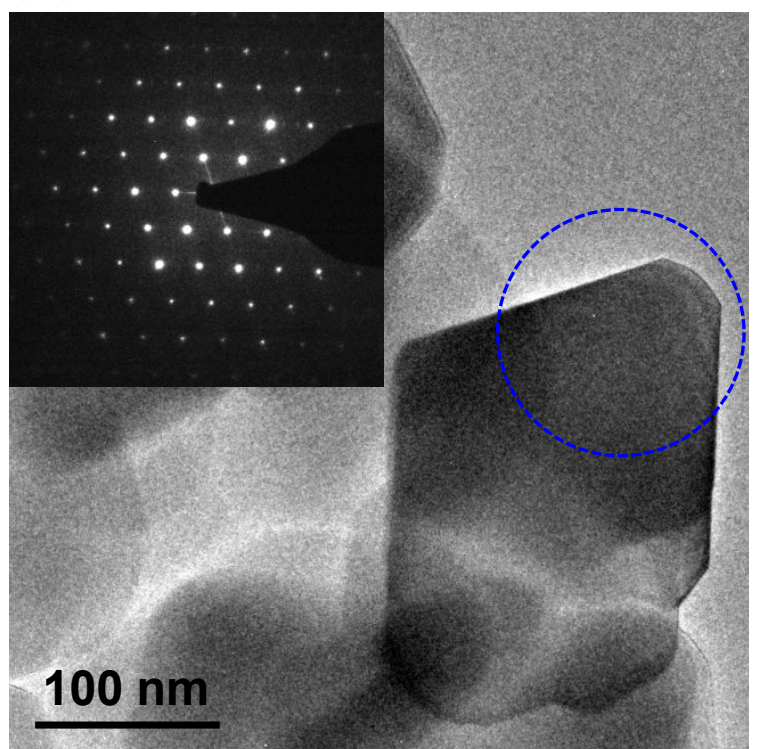

\section{(c): LTO}

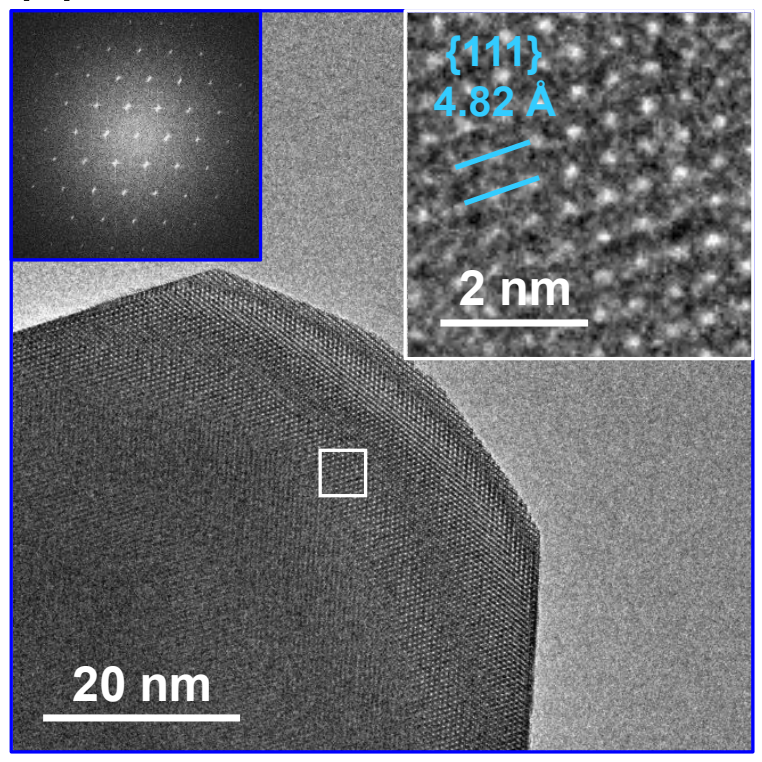

(b): NTO

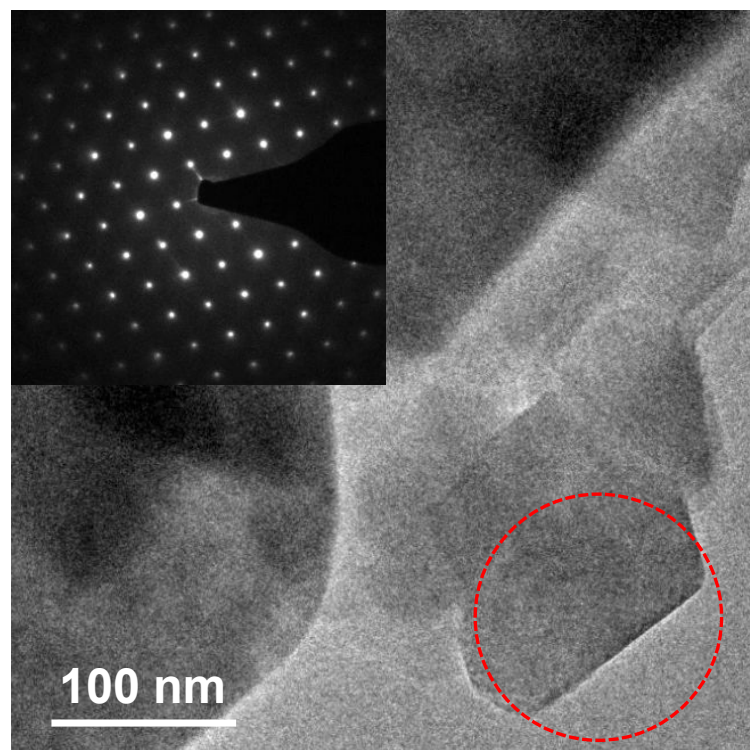

(d): NTO

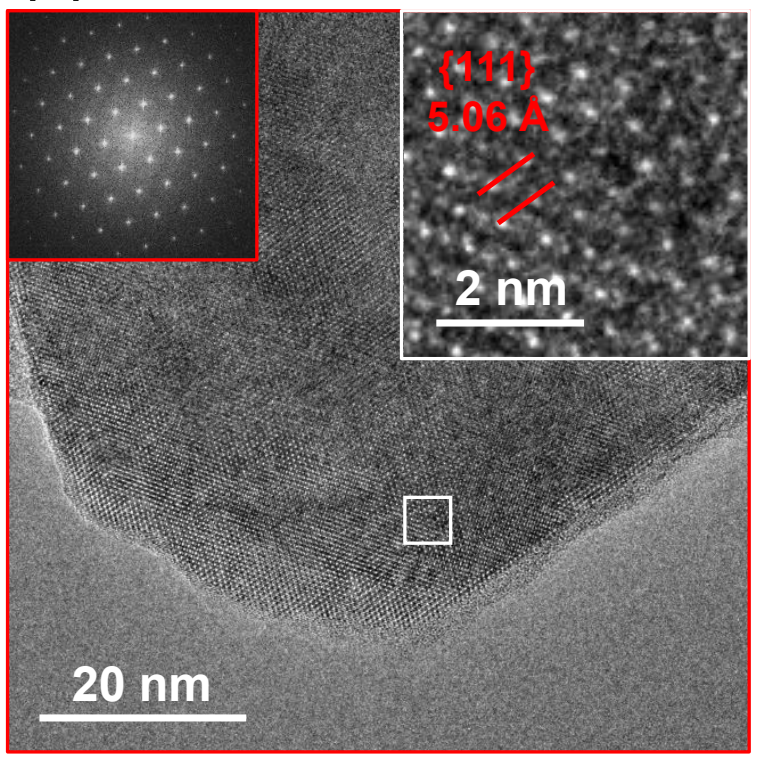

Figure S2 TEM investigation of the crystalline feature for primary particle of LTO and NTO powder samples. Low-magnification TEM images of (a) LTO and (b) NTO. Selected area electron diffraction patterns of $\{110\}$ zone-axis as shown in inset figure were acquired from the dot circle area in each images. Each diffractgrams showed single-crystalline spinel structure. 
This feature showed each samples were single phase materials even in the primary particle level. High-magnification TEM images of (c) LTO and (d) NTO. Two dimensional Fourier transform patterns of each images were also shown in inset figures. These patterns showed single-crystalline spots of spinel structure of $\{110\}$ zone-axis, meaning these particles consist of single-phase with high crystallinity. The high-resolution images of each particles expanded from white square area were also shown in inset figures. Where plane distance of $\{111\}$ lattice fringes were different in each other as $4.82 \AA$ for LTO and $5.06 \AA$ for NTO, respectively. They are corresponding into the lattice constant with $\mathrm{a}=8.35 \AA$ for LTO and $\mathrm{a}=8.76 \AA$ for NTO, respectively. These results were well corresponding into the results of SR-XRD. 


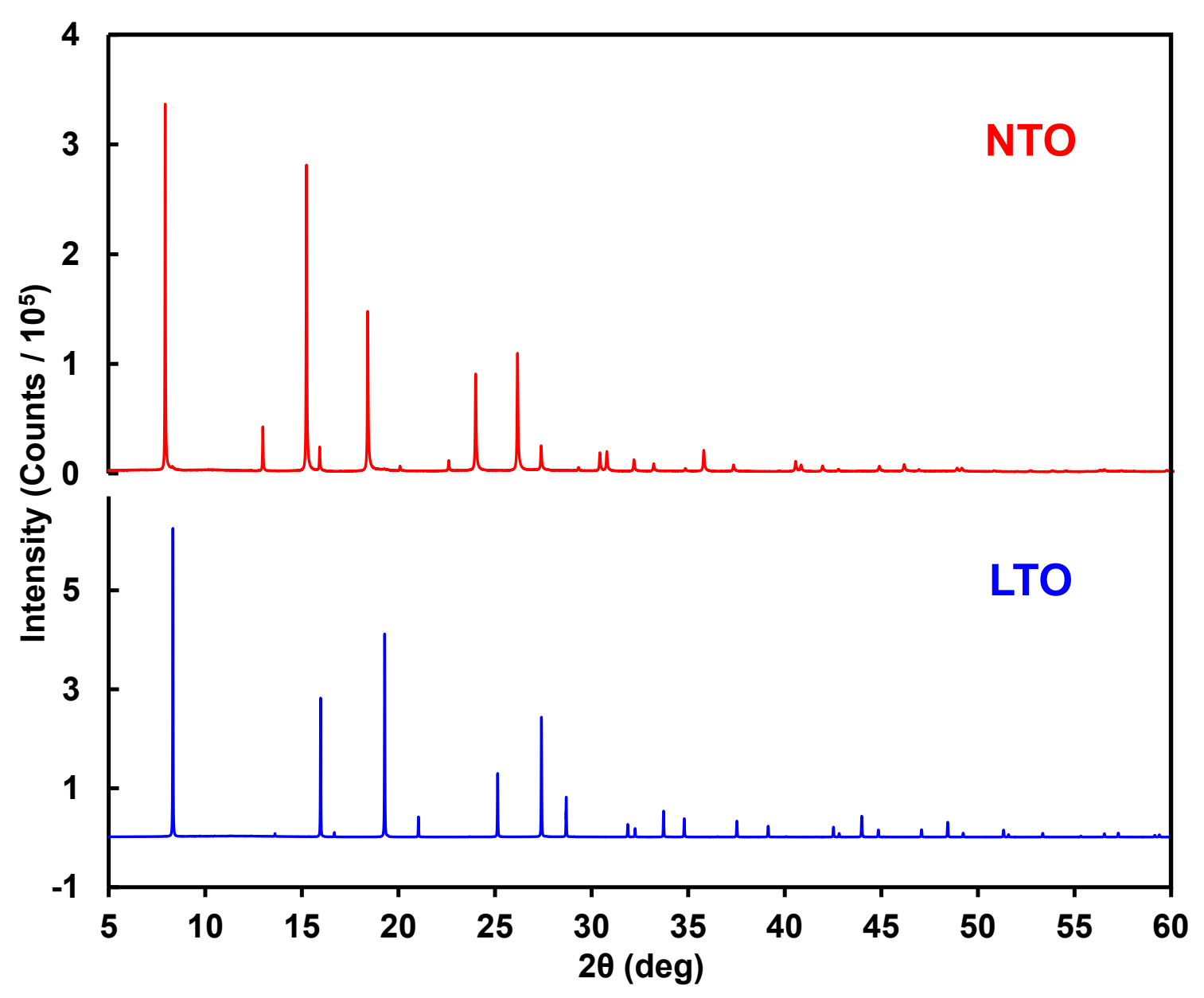

Figure S3 Synchrotron radiation X-ray diffraction (SR-XRD) spectra of pristine LTO (blue) and purified NTO (red), respectively. 


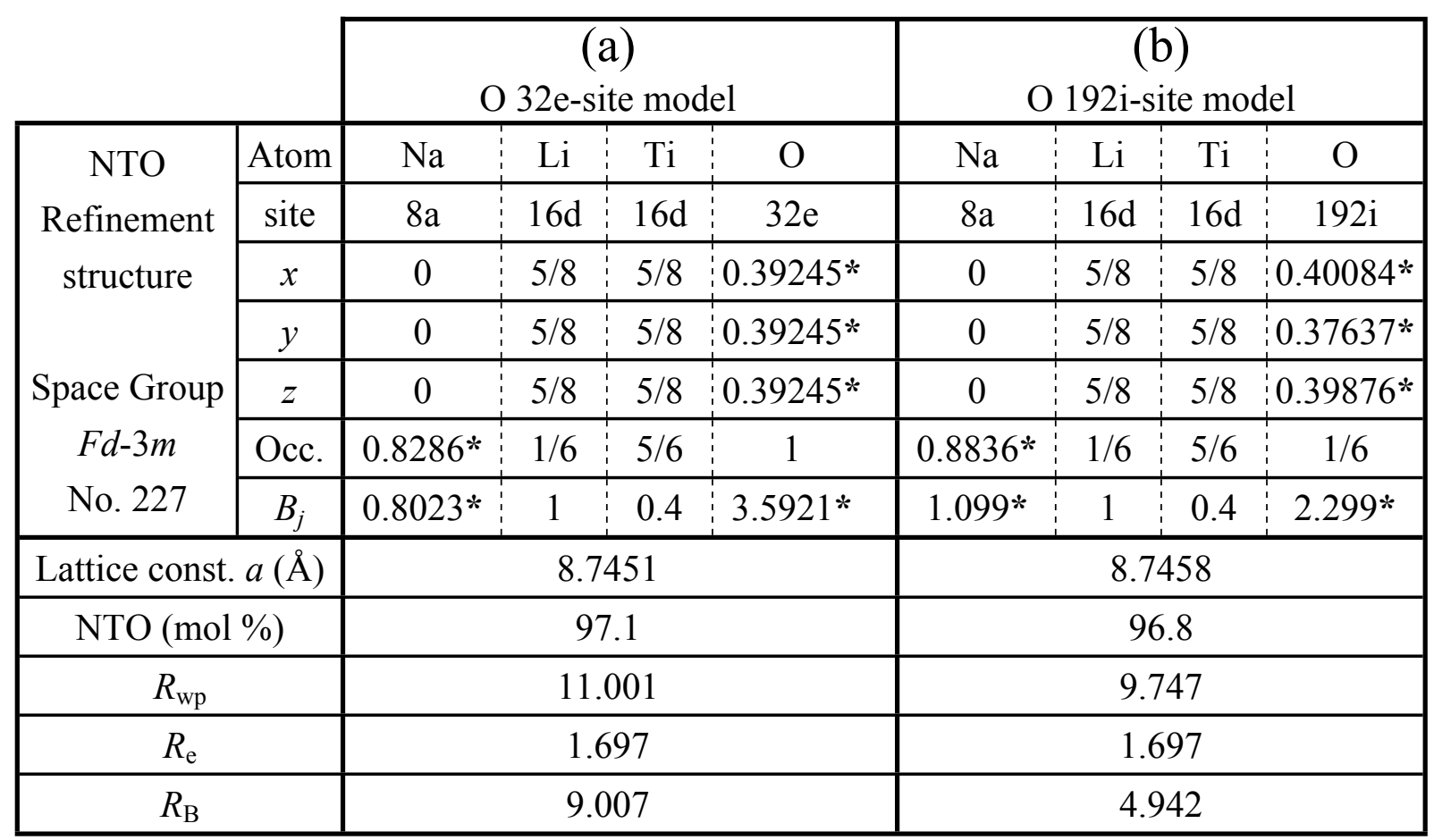

Table S2 Detail results of the Rietveld refinement of the NTO powder diffraction patterns of SR-XRD spectra with two-type of refinements model. The refined parameters were marked by * in the table. (a) A result for O 32e-site model, where coordination of $\mathrm{O}$ atom position is fixed as $(x, x, x)$ in the spinel $F d-3 m$ space group symmetry with original choice No1. (b) O site relaxation structure with O $192 \mathrm{i}$-site model as $(x, y, z)$ coordination. Where, occupancy of 192isite is $1 / 6$, corresponding to the same oxygen stoichiometry with O $32 \mathrm{e}$-site model. Oxygen $B_{j}$ parameter of $\mathrm{O}$ in 192i-site model is smaller than that of $\mathrm{O}$ in 32e-site model, means oxygen coordination of NTO crystal should be well optimizing with more variable $\mathrm{O}$ atom position. Where, refinement reliable factors $\left(R_{\mathrm{wp}}, R_{\mathrm{B}}\right)$ showed more small value in 192i-site refinement result. It should be suggesting that the variation of oxygen site is essential for NTO crystal. 
(a)

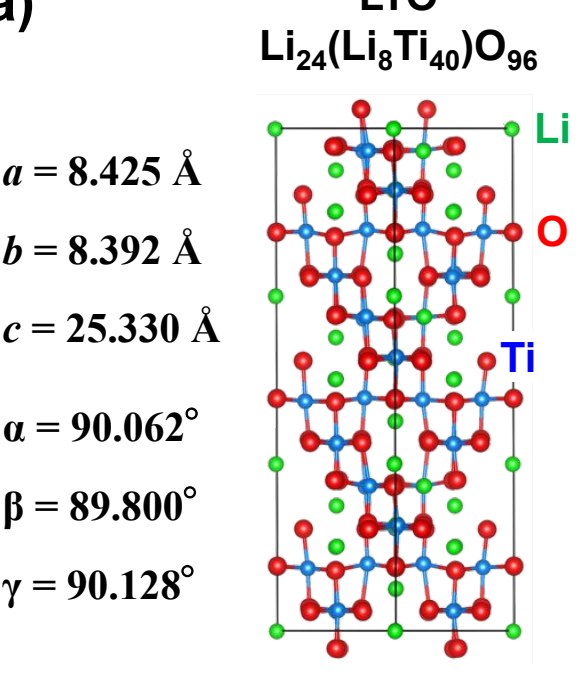

NTO

$\mathrm{Na}_{24}\left(\mathrm{Li}_{8} \mathrm{Ti}_{40}\right) \mathrm{O}_{96}$

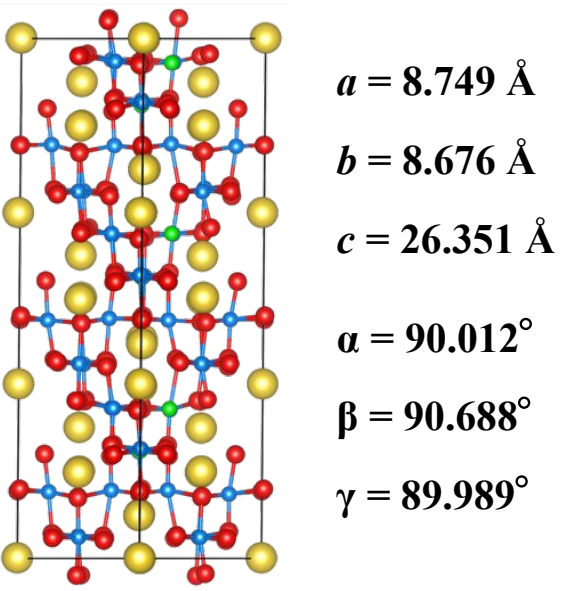

(b)
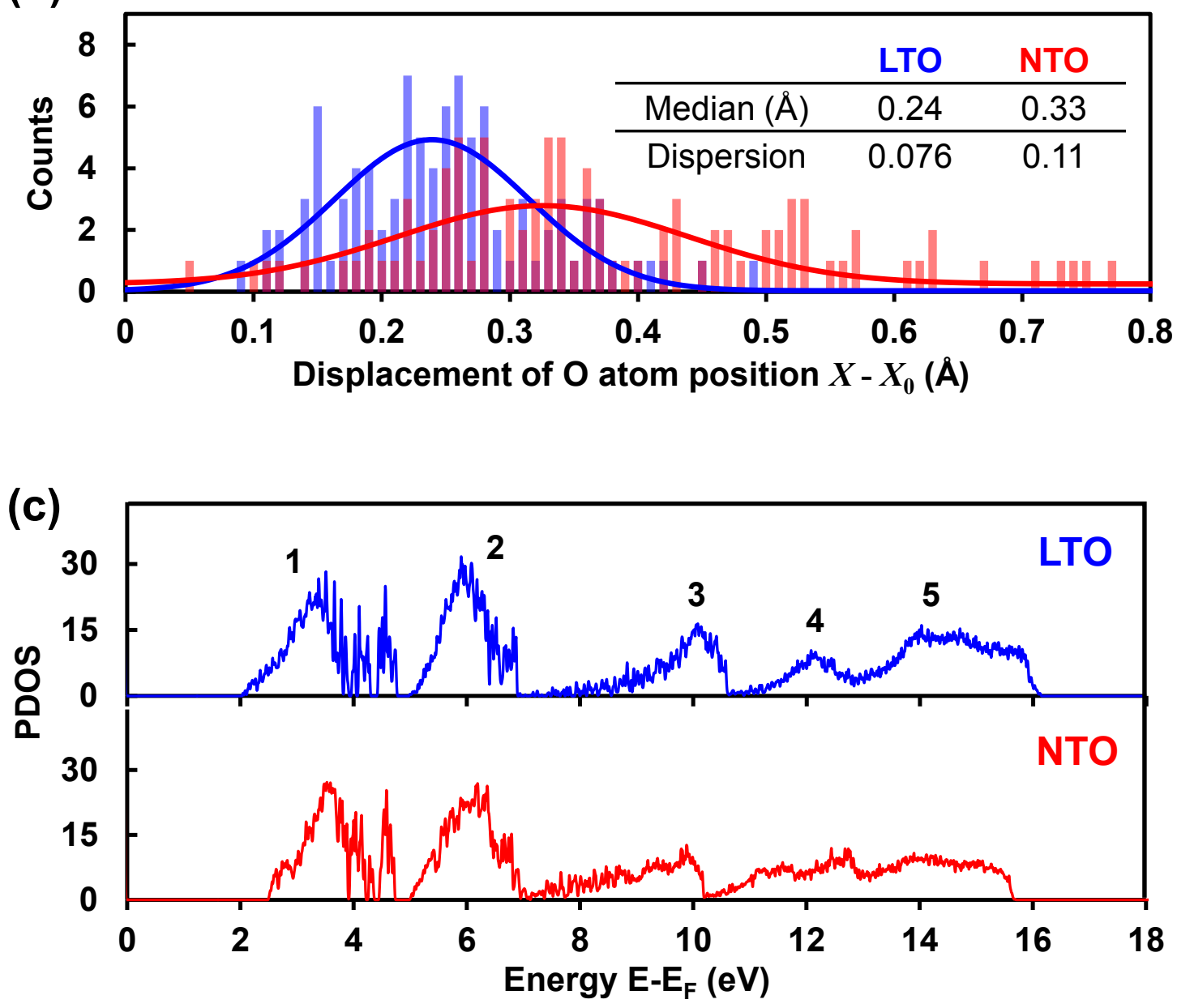
Figure S4 Theoretical simulation of LTO and NTO crystal models by density functional theory (DFT). The generalized gradient approximation formula by Perdew-Burke-Ernzerhof was used for the exchange-correlation functional. Projector augmented wave function (PAW) scheme was employed for treating core-electrons, which are $1 \mathrm{~s}(\mathrm{Li}), 1 s 2 s 2 p(\mathrm{Na}), 1 s(\mathrm{O})$, and $1 s 2 s 2 p 3 s$ (Ti). The cut-off energy of wave function was set to $450 \mathrm{eV}$. The $8 \times 8 \times 2$ Monkhorst mesh was used for $k$-points sampling. All DFT calculations were performed by Vienna ab initio simulation package (VASP). (a) Optimized lattice structure of LTO and NTO models with full atomic and cell relaxation by $P 1$ symmetry. Both crystals models were retained almost cubic spinel symmetry, while the lattice volume was different each other. The averaged lattice constant are estimated as $\tilde{a}=8.420 \AA$ and $\tilde{a}=8.736 \AA$ for LTO and NTO simulated lattice, respectively. These lattice constant are calculated as $a=8.36 \AA$ (LTO) and $a=8.746 \AA$ (NTO) for the refinement results of SR-XRD spectra, therefore theoretical lattice parameters are well corresponding to the experimental results. Both simulated models were rendered from the view of same $<110>$ crystal direction, where $\mathrm{Li}$ (green), $\mathrm{Ti}$ (blue) and $\mathrm{Na}$ (yellow) spheres are fixed similar position in each lattice models. (b) Histogram of position difference of $\mathrm{O}$ atoms between ideal $\left(X_{0}\right)$ and after relaxation $(X)$ positions. LTO and NTO are displaying with blue and red solid bars, respectively. The Gaussian fitting for each histograms were shown in solid lines with corresponding colors. Where medians and dispersions for each fitting curves were summarized in inset table. While the $\mathrm{O}$ atoms are more disturbed in the NTO lattice than that of LTO, and this was well corresponding into the results of Rietveld refinement, that suggesting the wide variation of oxygen positions of NTO. (c) Summation of projected density of states (PDOS) spectra of all O-2p orbitals of LTO (blue) and NTO (red) simulated lattice at empty state region. Both spectra were closely resembled in the 2 to $8 \mathrm{eV}$ energy region at peak 1 and 2 , respectively. These DOS peaks are corresponding into the hybridization of O- $2 p$ and Ti- $3 d$ orbitals. Since the strong interaction to Ti-3d orbital with same oxidation state $\left(\mathrm{Ti}^{4+}\right)$, these $\mathrm{O}-2 p$ PDOS spectra 
should be reproduced similar in LTO and NTO structure. As for the peak 3 to 5 at the 8 to 16 eV energy region, where broadness of their spectra were remarkably different. Especially, peak 4 at 10 to $14 \mathrm{eV}$ energy region was slightly splitting in NTO spectra, while the LTO has single peak at same energy region. These different DOS structure should be derived from the difference of the detail electronic structure between LTO and NTO, where variety of oxygen position and hybridization of Na-3s would be provide more complex DOS structure for NTO lattice than LTO lattice. These simulated electronic structure should be reflected to the experimental EELS spectra, since the O- $K$ ELNES is highly affecting by the empty DOS of $O$ $2 p$ orbital due to its core-level electron transition between $\mathrm{O}-1 s$ to $\mathrm{O}-2 p$ state. 


\begin{tabular}{cccccc}
220 & 311 & 222 & $I_{222} / I_{311}$ & 400 \\
& $\begin{array}{c}\text { Intensity } \\
(\mathrm{cps} \cdot \mathrm{deg})\end{array}$ & $\begin{array}{c}\text { Intensity } \\
(\mathrm{cps} \cdot \mathrm{deg})\end{array}$ & $\begin{array}{c}\text { Intensity } \\
(\mathrm{cps} \cdot \mathrm{deg})\end{array}$ & $\begin{array}{c}\text { Intensity } \\
\text { Ratio }\end{array}$ & $\begin{array}{c}\text { FWHM } \\
(\mathrm{deg})\end{array}$ \\
\hline $\mathrm{A}$ & 322.397 & 3076.339 & 221.091 & 0.071 & 0.250 \\
\hline $\mathrm{B}$ & 40.748 & 811.045 & 509.018 & 0.830 & 0.252 \\
\hline $\mathrm{C}$ & - & 265.799 & 614.810 & 2.760 & 0.246 \\
\hline $\mathrm{D}$ & 244.939 & 3068.801 & 408.174 & 0.131 & 0.241 \\
\hline $\mathrm{E}$ & 339.666 & 3664.489 & 308.041 & 0.089 & 0.243
\end{tabular}

Table S3 Analysis of 220 to 400 diffraction peaks with each Na-inserted state. The 220 intensity was reducing with depth of Na-insertion, while it revert to initial intensity after Na-extraction. The reversible intensity alternation of 220 diffraction peak showed that the $\mathrm{Na}$ in $8 \mathrm{a}$-site would be shift to other spinel site with Na-insertion and return to its original position with Naextraction. The absolute intensity and intensity ratio of 311 and 222 diffraction peaks showed this $\mathrm{Na}$ site alternation feature. Peak intensity of 311 diffraction was decreasing while 222 diffraction was increasing with depth of Na-insertion. The intensity of 222 diffraction peak reached to almost 3 times higher than that of 333 peak at the full Na-inserted state. These feature was well corresponding to the XRD simulation of 8a and 16c-site models of Na in NTO lattice as shown in Figure 6(b). Full width at half maximum (FWHM) of 400 diffraction peak were not so altered, around $0.250 \mathrm{deg}$, in each Na-inserted state for A to E. Therefore, the spinel lattice framework should be rigid and strongly stable during Na-insertion and extraction cycles. Additionally, there no peak splitting was observed during cycle. Therefore solid-solution like structural alternation would be more proper than simple two-phase transition mechanism, as the electrochemical mechanism of NTO phase. 
(a)

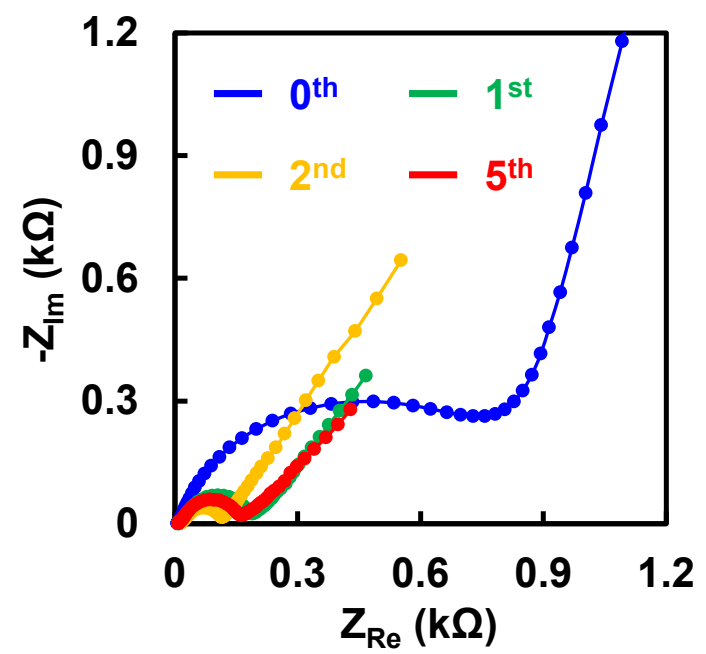

(b)

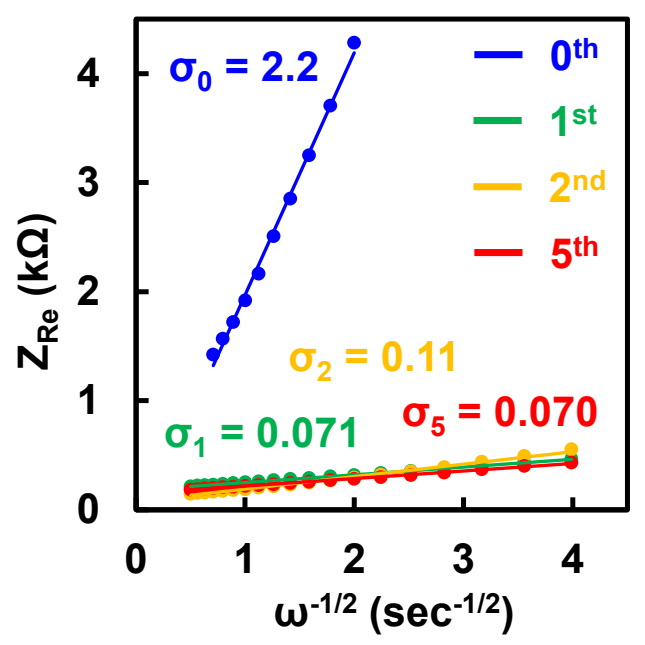

Figure S5 Electrochemical impedance spectroscopy (EIS) measurement of NTO / Na half-cell at initial Na-insertion and extraction cycles. The charge-discharge cycle was performed under $10 \mathrm{mAh} \mathrm{g}^{-1}$ of current density with 0.3 to $2.0 \mathrm{~V}$ vs. $\mathrm{Na}^{+} / \mathrm{Na}$ of voltage range. EIS measurement was performed for identical electrochemical cell as follows, as-assembled (non-cycle, $0^{\text {th }}$ ), after 1 cycled $\left(1^{\text {st }}\right), 2$ cycled $\left(2^{\text {nd }}\right)$ and 5 cycled $\left(5^{\text {th }}\right)$ state, respectively. Each experiments were recorded at $1 \mathrm{MHz}$ to $10 \mathrm{mHz}$ of frequency range with $5 \mathrm{mV}$ of amplitude voltage under open circuit voltage (OCV) condition. (a) Cole-cole plot of each experiment. At first, as-assembled electrochemical cell $\left(0^{\text {th }}\right)$ showed large semi-circle in its Nyquist-diagrams, suggested the cell has large interface resistance. On the other hand, the resistance were clearly decreased for 1 to 5 cycled. (b) $Z_{\mathrm{Re}}$ vs. $\omega^{-1 / 2}$ plot of each experiments. Here the slope of linear plots $(\sigma)$ is related with Na-ion diffusion coefficient in the electrode $\left(D_{\mathrm{Na}+}\right)$ as $\sigma \propto D_{\mathrm{Na}^{+}}{ }^{-1 / 2}$, therefore the low value of $\sigma$ means high Na-ion conductivity. ${ }^{\mathrm{S} 1}$, S2 There, as-assembled electrochemical cell $\left(0^{\text {th }}\right)$ showed larger value of $\sigma$, while it was reducing in 1 to 5 cycled state. Thus the stabilization of charge-discharge performance of NTO / Na half-cell during initial few cycles should be explained by decreasing of cell resistance and increasing of Na-ion conductivity, as an 
activation behavior of electrode.
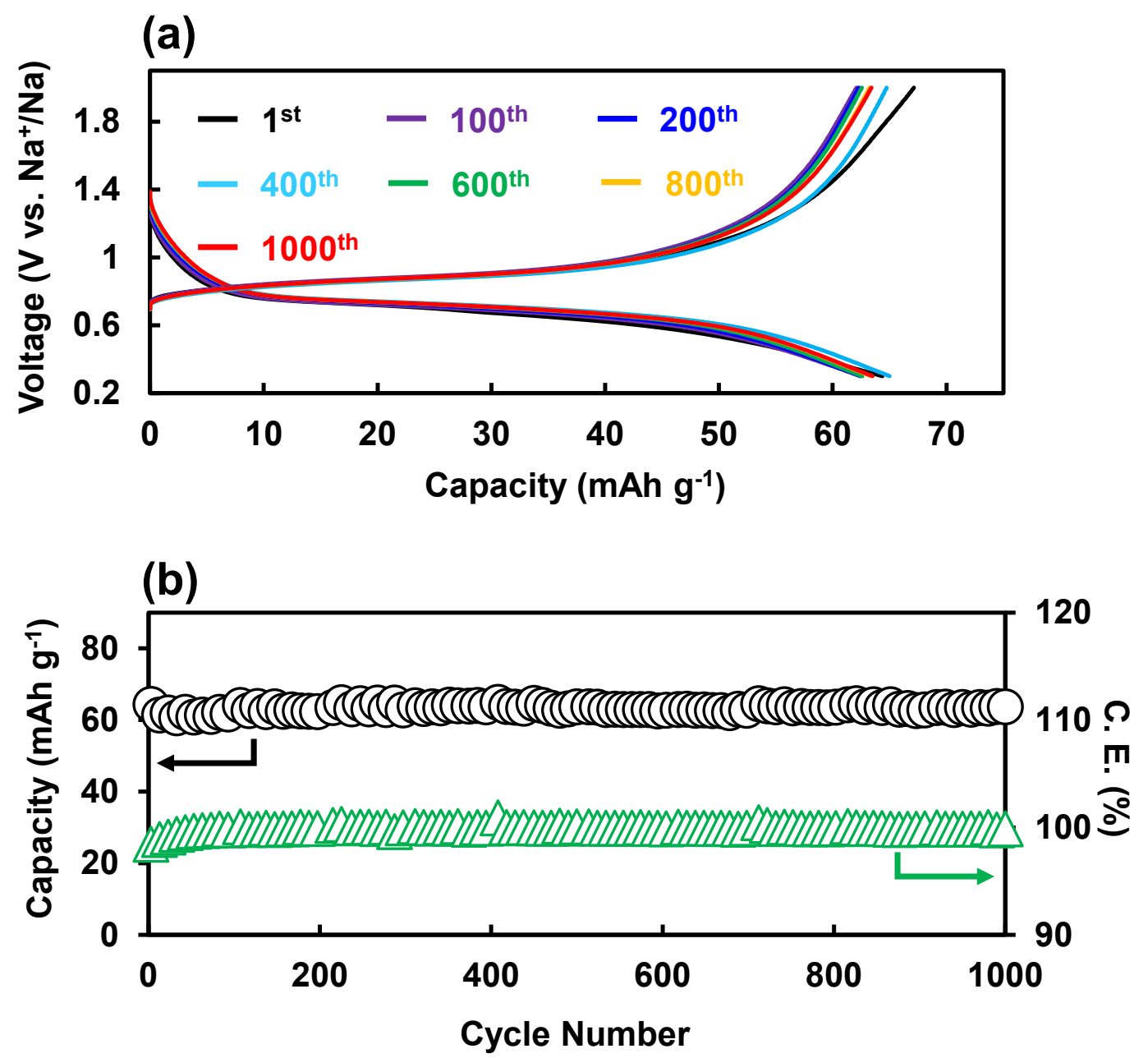

Figure S6 Long-term cycle test for NTO / Na half-cell with $0.8 \mathrm{C}\left(=120 \mathrm{~mA} \mathrm{~g}^{-1}\right)$ current density of charge-discharge. About $0.5 \mathrm{mg}$ (NTO) $\mathrm{cm}^{-2}$ disc electrode was used to keep the stability of Na-metal counter electrode during long cycle. (a) Charge-discharge voltage profiles of several cycles during 1000 cycle test. Voltage profiles were well reproducible, suggesting stable charge-discharge reaction performance. (b) Cycle plots of $\mathrm{Na}$ insertion capacity (black circle) and Coulombic efficiency (green triangle) for every 10 
cycles.

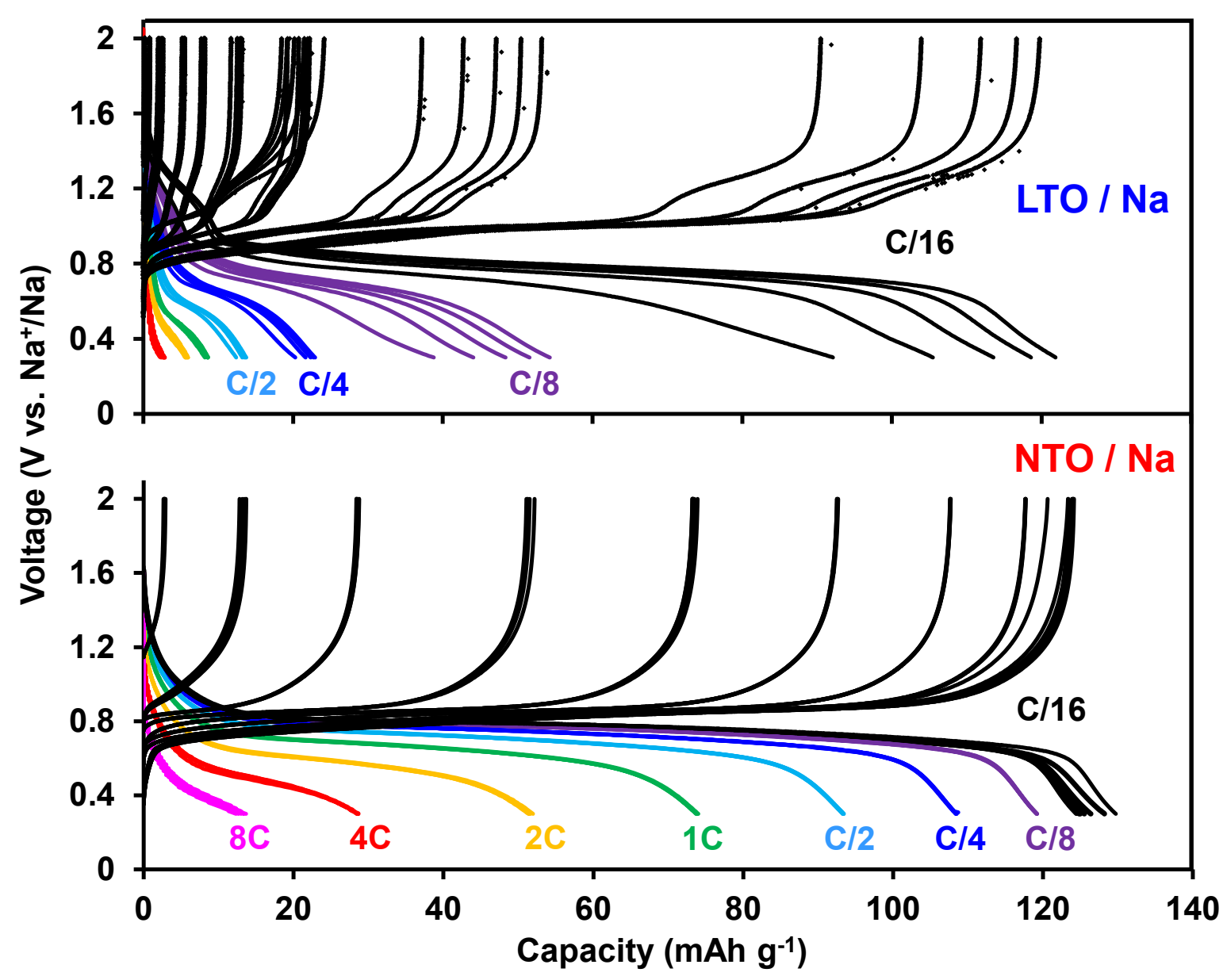

Figure S7 Na-insertion properties of pristine LTO and NTO / Na half-cell with various C-rate.

Pristine LTO electrode showed poor Na-insertion C-rate property since its low $\mathrm{Na}^{+}$diffusion as shown in Figure S8. 
(a)

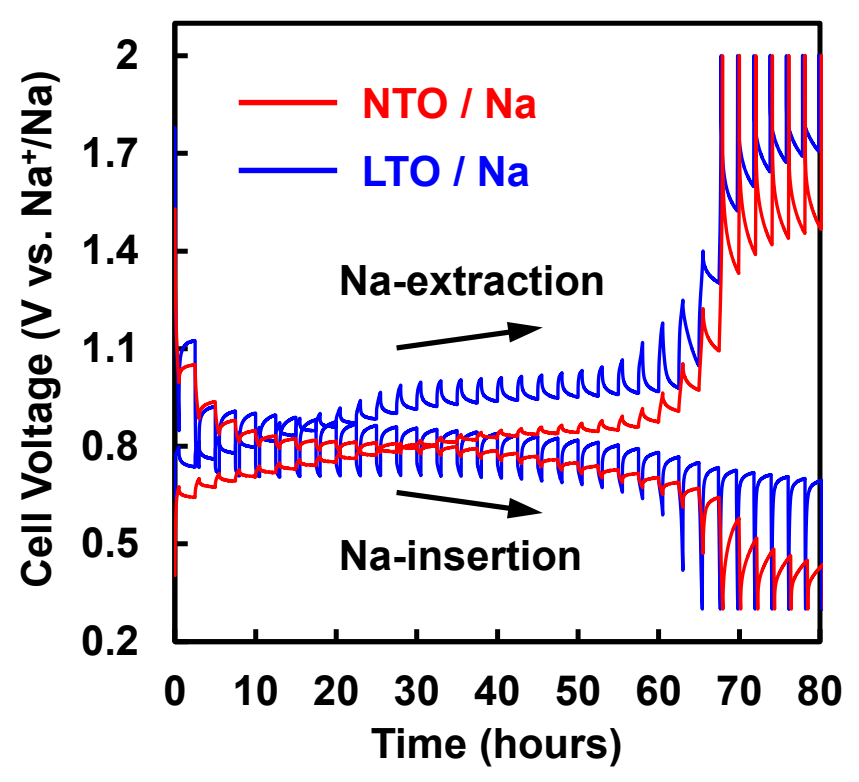

(c)

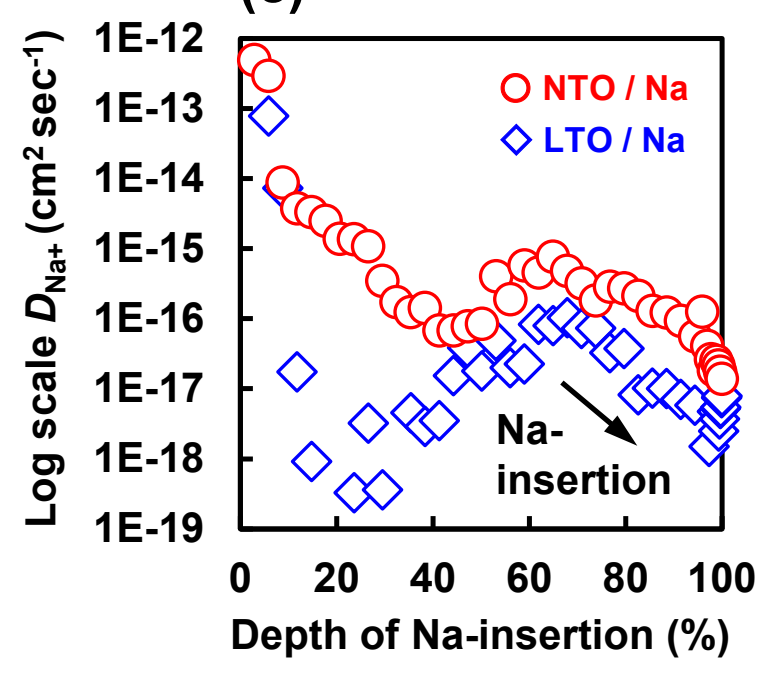

(b)

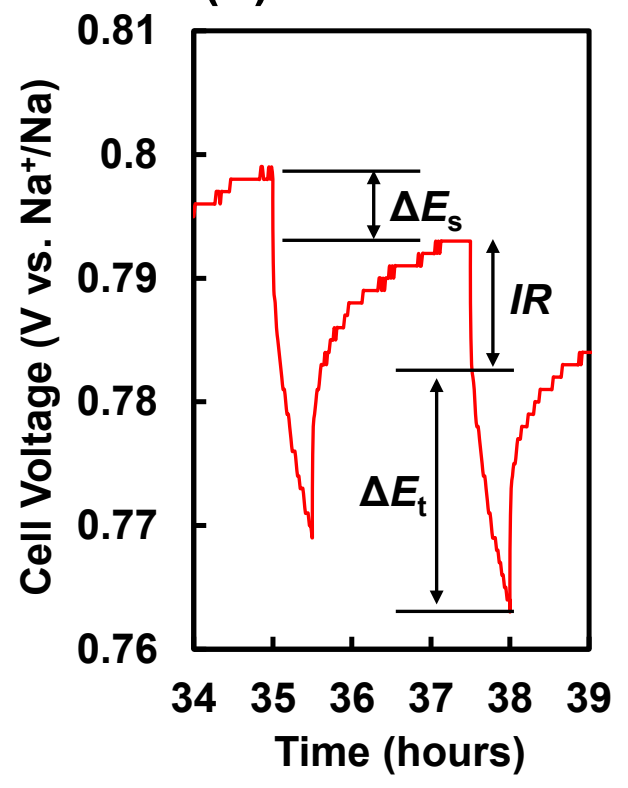

(d)

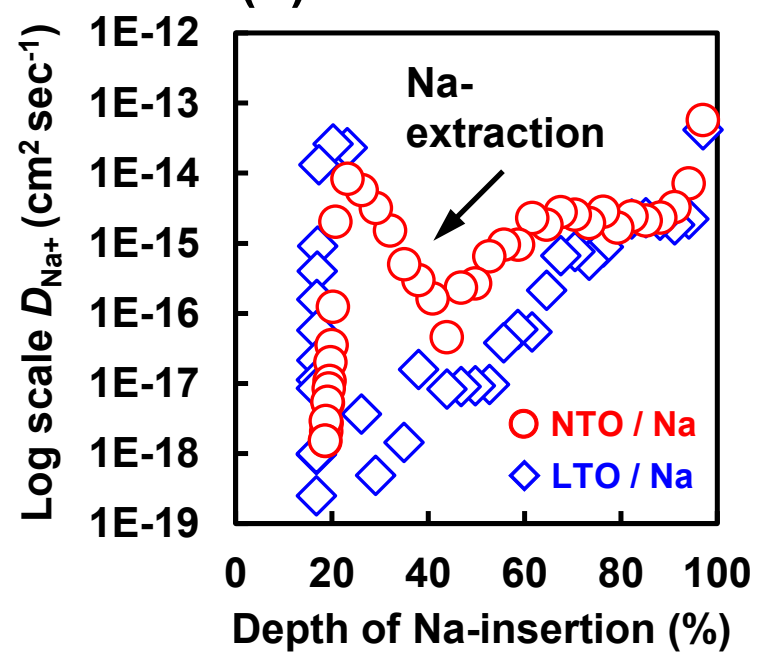

Figure S8 Sodium diffusion coefficient $\left(D_{\mathrm{Na}^{+}}\right)$analysis of LTO and NTO materials in each Na- 
ion half-cells during cycling by galvanostatic intermittent titration technique (GITT). ${ }^{\mathrm{S} 3}$ The titrations were carried out by applying square current pulses of $10 \mathrm{~mA} \mathrm{~g}^{-1}$ for $\tau=30$ minutes, followed by potential relaxation step of $2 \mathrm{~h}$ at the open circuit voltage. The procedure was continued until the cell potential reaches to $0.3 \mathrm{~V}$ (Na-insertion) or $2.0 \mathrm{~V}$ (Na-extraction). (a) Potential profiles of LTO (blue) and NTO (red) electrode in Na-ion half-cells during GITT measurement. Electrochemical polarization of NTO electrode was smaller than LTO electrode, supporting that electrochemical charge-discharge reaction of NTO should be superior to LTO electrode. (b) A typical magnified GITT potential profile of NTO electrode during Na-insertion reaction. Where $\Delta E_{\mathrm{s}}$ is the steady-state voltage change, and $\Delta E_{\mathrm{t}}$ is the voltage change during the constant current pulse, excluding the $I R$ drop. The $\mathrm{Na}^{+}$diffusion coefficient $D_{\mathrm{Na}}$ can be calculated at each step, with the following formula,

$$
D_{\mathrm{Na}+}=\frac{4}{\pi}\left(\frac{I V_{m}}{z_{A} F S}\right)\left(\frac{d E}{d \delta} / \frac{d E}{d \sqrt{t}}\right)^{2}
$$

Here, $I$ is the current (A), $V_{m}$ is the molar volume of the electrode $\left(\mathrm{cm}^{3} / \mathrm{mol}\right), \mathrm{z}_{\mathrm{A}}$ is the charge number, $F$ is the Faraday's constant, $S$ is the electrode / electrolyte contact area $\left(\mathrm{cm}^{2}\right), d E / d \delta$ is the slope of the coulometric titration curve, found by plotting the steady state voltages $E(V)$ measured after each titration step $\delta$ and $d E / d t^{1 / 2}$ is the slope of the linearized plot of the potential $E(\mathrm{~V})$ during the current pulse of duration $t$ (s). If sufficient small currents are applied for short time intervals, so that $d E / d \mathrm{t}^{1 / 2}$ can be considered linear and the coulometric titration curve can be also considered linear over the composition range involved in that step, Equation S3 can be simplified as follows,

$$
D_{\mathrm{Na}+}=\frac{4}{\pi \tau}\left(\frac{n_{\mathrm{m}} V_{\mathrm{m}}}{S}\right)\left(\frac{\Delta E_{S}}{\Delta E_{t}}\right)^{2}
$$


Here, $\tau$ is the duration of the current pulse $(1800 \mathrm{sec}), n_{\mathrm{m}}$ is the number of moles (mol) of electrode materials, $V_{\mathrm{m}}$ is the molar volume of the electrode $\left(\mathrm{cm}^{3} / \mathrm{mol}\right), \quad S$ is the electrode/electrolyte contact area $\left(\mathrm{cm}^{2}\right)$. By equation $\mathrm{S} 4$, the Na diffusion coefficient $\left(D_{\mathrm{Na}+}\right)$ of LTO (blue square) and NTO (red triangle) electrode materials were calculated and summarized in (c) and (d) as Log scale $D_{\mathrm{Na}^{+}}$Vs. depth of Na-insertion plots. Where $\mathrm{Na}^{+}$diffusion coefficient during Na-insertion and Na-extraction reaction was estimated to $D_{\mathrm{Na}^{+}}=10^{-17}$ to $10^{-16} \mathrm{~cm}^{2} / \mathrm{sec}$ for NTO and $D_{\mathrm{Na}^{+}}=10^{-19}$ to $10^{-17} \mathrm{~cm}^{2} / \mathrm{sec}$ for LTO, respectively. Therefore, Na-insertion and Na-extraction rate of NTO should be 10 to 100 times superior to LTO electrode. The lattice expanded spinel NTO phase $(a=8.745 \AA)$ should provide more facile $\mathrm{Na}^{+}$diffusion than smaller LTO lattice $\left(a=8.36 \AA\right.$ ). The $\mathrm{Na}^{+}$diffusion would be facile for Na-insertion and extraction, meaning high in / out-put power density cells could be constructed with NTO electrode. 


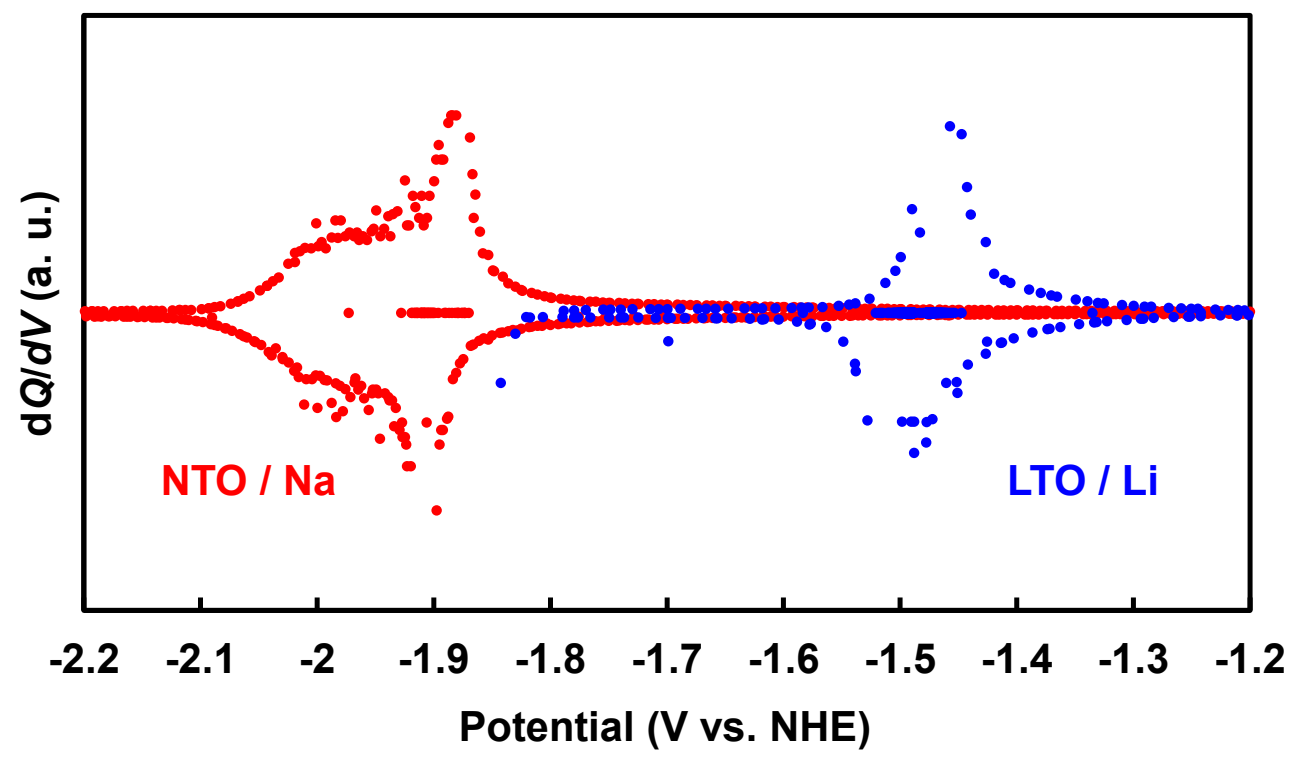

Figure S9 The $d Q / d V$ plots corresponding to the voltage profiles of NTO / Na and LTO / Li half cells in Figure 8. The plot of LTO / Li half-cell (blue dots) showed single peak feature with both Li-insertion and extraction. However, the plots of NTO / Na half-cell (red dots) showed slightly broader feature at lower potential side of redox-peak. The Na-insertion and extraction feature should be slightly different with LTO / Li half-cell well-known as simple two-phase conversion mechanism. 


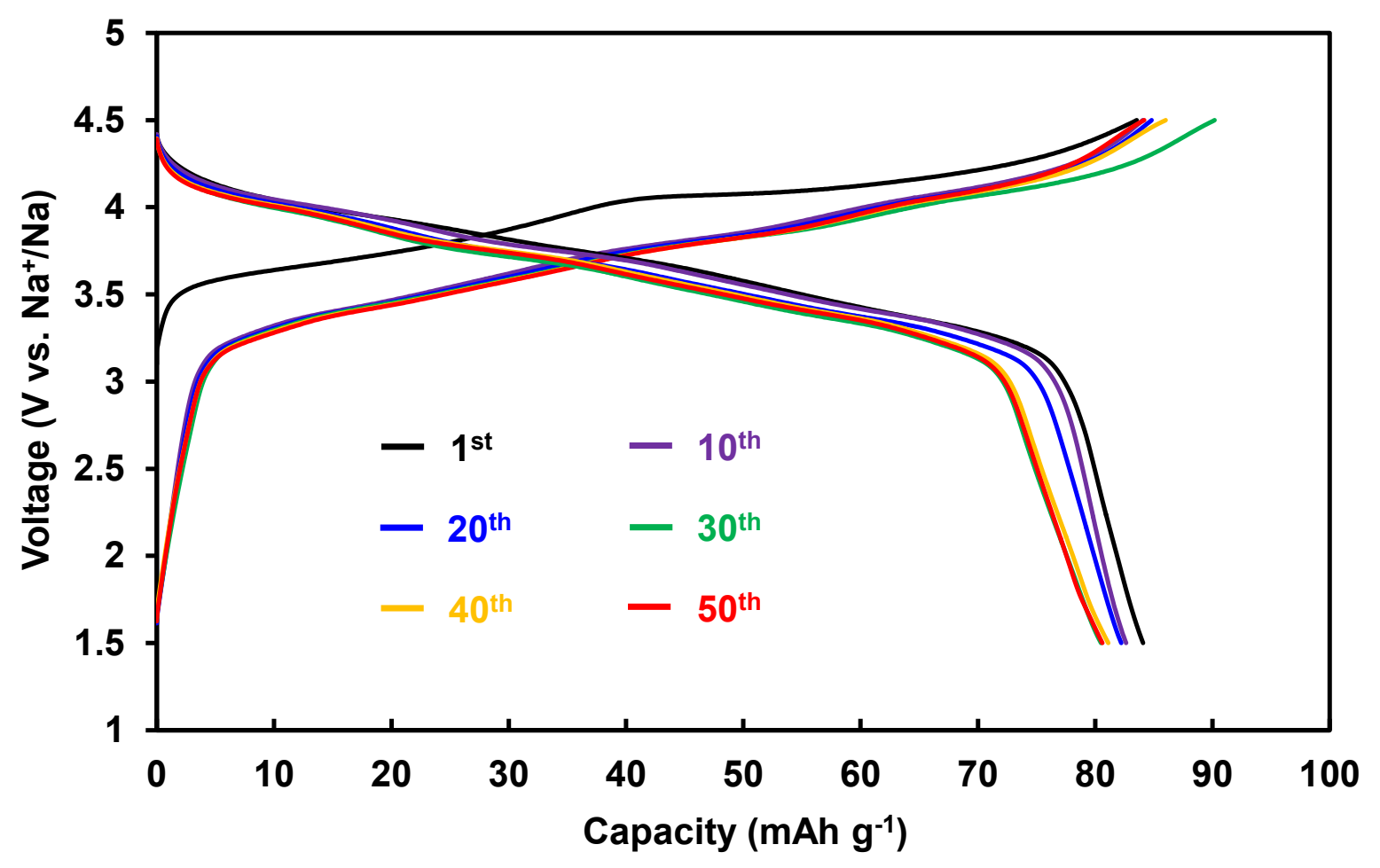

Figure S10 Galvanostatic charge-discharge profiles of $\mathrm{Na}_{2} \mathrm{Fe}_{2}\left(\mathrm{SO}_{4}\right)_{3} / \mathrm{Na}$ half-cell till 50 cycles. The current density and cut-off range were set to $10 \mathrm{~mA} \mathrm{~g}-1$ and 1.5 to $4.5 \mathrm{~V}$ vs. $\mathrm{Na}^{+} / \mathrm{Na}$, respectively. The mass of positive electrode material is about $8.6 \mathrm{mg}$ in this experiment. About 70 to $80 \mathrm{mAh} \mathrm{g}^{-1}$ of specific capacities were confirmed. 


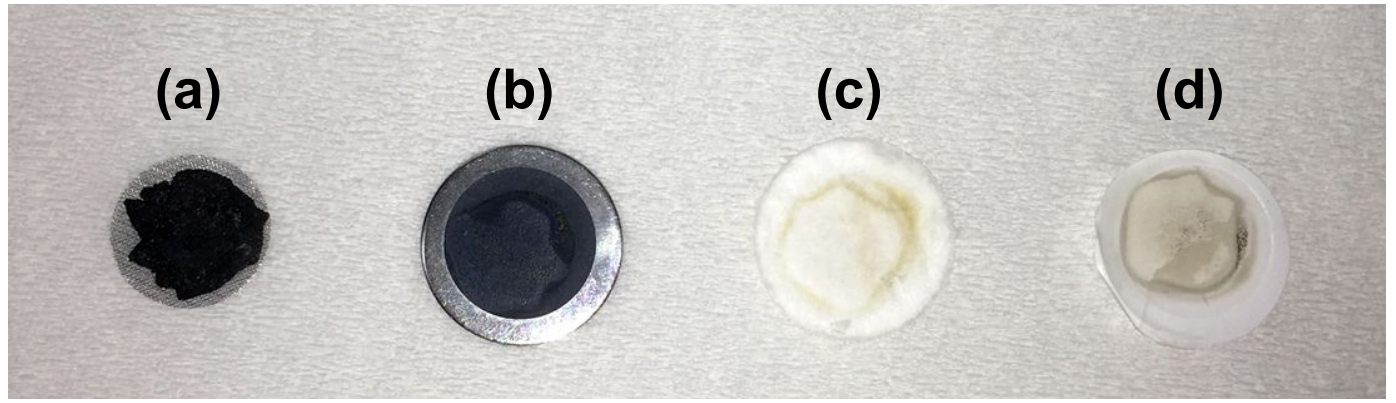

Figure S11 Photographs of full-cell components after 100 cycles. (a) $\mathrm{Na}_{2} \mathrm{Fe}_{2}\left(\mathrm{SO}_{4}\right)_{3}$ positive electrode, (b) NTO negative electrode, (c) glass-filter and (d) polypropylene separator film. These pictures were acquired at dry-air filled box. Deposited Na-metal cannot be seen in all the component, suggested that the superior safety properties of full-cell operation. 

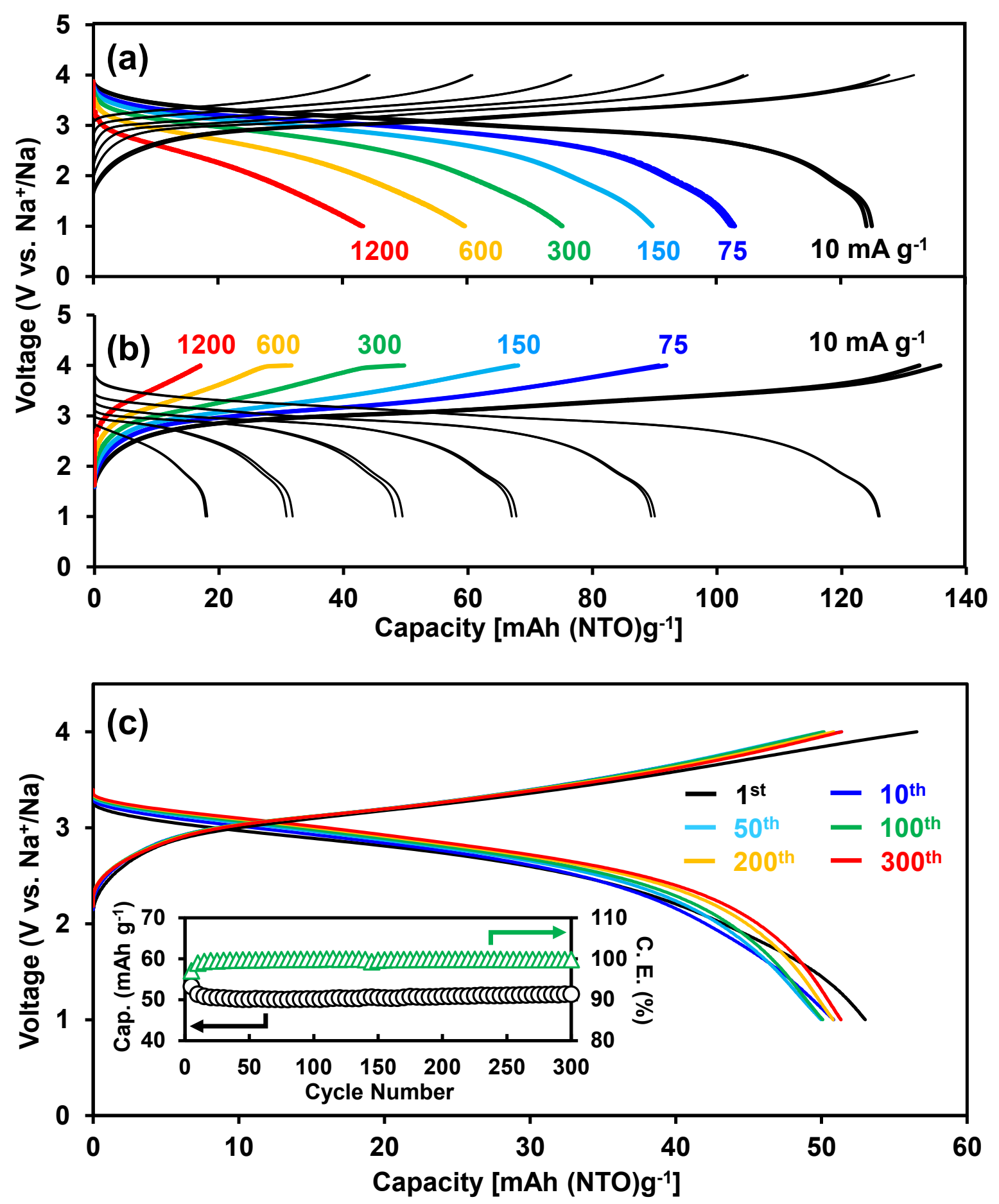

Figure S12 Charge-discharge performance of $\mathrm{Na}_{2} \mathrm{Fe}_{2}\left(\mathrm{SO}_{4}\right)_{3} / \mathrm{NTO}$ full-cell with various current density of discharge (a) and charge (b). Current densities [mA (NTO) $\left.\mathrm{g}^{-1}\right]$ were presented at beside profiles. The profiles showed voltage plateau at even $1200 \mathrm{~mA} \mathrm{~g}^{-1}$ of current density. The discharge profiles retained $90 \mathrm{mAh} \mathrm{g}^{-1}$ at $150 \mathrm{~mA} \mathrm{~g}^{-1}$, promising high out-put properties of this full-cell. (c) Long-term cycle properties of full-cell. The charge-discharge 
current density was set to $150 \mathrm{~mA} \mathrm{~g}^{-1}$. Voltage profiles were well reproducible more than 300 cycles with $3.0 \mathrm{~V}$ of averaged cell voltage. Cycle plots with every 5 cycles in inset, also showed stable performance. 


\section{References}

(S1) Kitta, M.; Kuratani, K.; Tabuchi, M.; Takeichi, N.; Akita, T.; Kiyobayashi, T.; Kohyama, M. Irreversible Structural Change of a Spinel $\mathrm{Li}_{4} \mathrm{Ti}_{5} \mathrm{O}_{12}$ Particle via $\mathrm{Na}$ Insertion-Extraction Cycles of a Sodium-Ion Battery. Electrochim. Acta 2014, 148, 175-179.

(S2) Kitta, M.; Kuratani, K.; Tabuchi, M.; Kataoka, R.; Kiyobayashi, T.; Kohyama, M. Design of a Sodium-ion Cell with a Carbon-free $\mathrm{Li}_{4} \mathrm{Ti}_{5} \mathrm{O}_{12}$ Negative Electrode. Electrochemistry 2015, 83, 989-992.

(S3) "Galvanostatic Intermittent Titration Technique" Available at:

http://www.autolabj.com/appl.files/appl\%20note2015/Autolab_Application_Note_BAT03.pdf Accessed 19 August 2019. 